\title{
Variation in morphology and branching pattern of superior mesenteric artery
}

\author{
K.M. Taha1, M.H. Karrar Alsharif2, 4 , A.Y. Elamin ${ }^{3,4}$ \\ ${ }^{1}$ Anatomy Department, Faculty of Medicine, University of Science and Technology, Khartoum, Sudan \\ ${ }^{2}$ Anatomy Department, Faculty of Medicine, Prince Sattam Bin Abdulaziz University, Al-Kharj, Kingdom of Saudi Arabia \\ ${ }^{3}$ Emergency Medical Specialist Department, Al-Ghad International Colleges for Applied Medical Sciences, Al Madinah \\ Al Munawarah, Kingdom of Saudi Arabia \\ ${ }^{4}$ Histology and Embryology Department, College of Medicine, Ondokuz Maiz University, Samsun, Turkey
}

[Received: 20 April 2016; Accepted: 4 July 2016]

\begin{abstract}
The anatomical variations of superior mesenteric artery branches are common. In this study we reported an extraordinary morphology and branching of superior mesenteric artery, during our routine dissection of a 38-year-old Sudanese male cadaver, where the superior mesenteric artery forms an arch over the confluence of inferior vena cava and left renal vein.

Other variations observed were: 1) The superior mesenteric artery shares the same origin of coeliac trunk; 2) The unusual origin of right hepatic artery.

We think that the knowledge of these variations plays an important role in conducting and planning of radiological and surgical procedures especially in hepatobiliary and pancreatic surgery. Morphology and branching patterns of this artery is anecdotic, which makes this case the most unique. (Folia Morphol 2017; 76, 3: 532-535)
\end{abstract}

Key words: superior mesenteric artery, coeliac trunk, right hepatic artery, right gastro-omental artery

\section{INTRODUCTION}

Through the knowledge the superior mesenteric artery, which is also called the artery of midgut [10], acts as an axis which about the rotation of the gut takes place [9].

It arises from the ventral surface of abdominal aorta at the level of first lumbar vertebra and sends about 15-18 branches which supply the gut from the middle of the duodenum to the junction between right two-third and left one-third of transverse colon [6] as seen in Figure 1 [3].

It is directed steeply downwards behind the splenic vein and the neck of the pancreas. With the superior mesenteric vein on its right side it lies on the left renal vein, then on the uncinate process of the pancreas and then on the third part of the duodenum [11].

After the ileocolic artery origin, the superior mesenteric artery gives off ileal branches only. It is a continuous vessel that gradually decreases in diameter and anastomoses with the ileal branch of the ileocolic artery. Except from its jejunal, ileal and colic branches, the superior mesenteric artery also gives pancreatic and duodenal branches (pancreaticoduodenal arcades, the artery for the neck of pancreas, the transverse pancreatic artery and a branch for the duodenojejunal angle). Bizarre branches from the superior mesenteric artery are the common hepatic

Address for correspondence: M.H. Karrar Alsharif, Anatomy Department, Faculty of Medicine, Prince Sattam Bin Abdulaziz University, Al-Kharj, Kingdom of Saudi Arabia, e-mail: dr.anatomy83@yahoo.com 


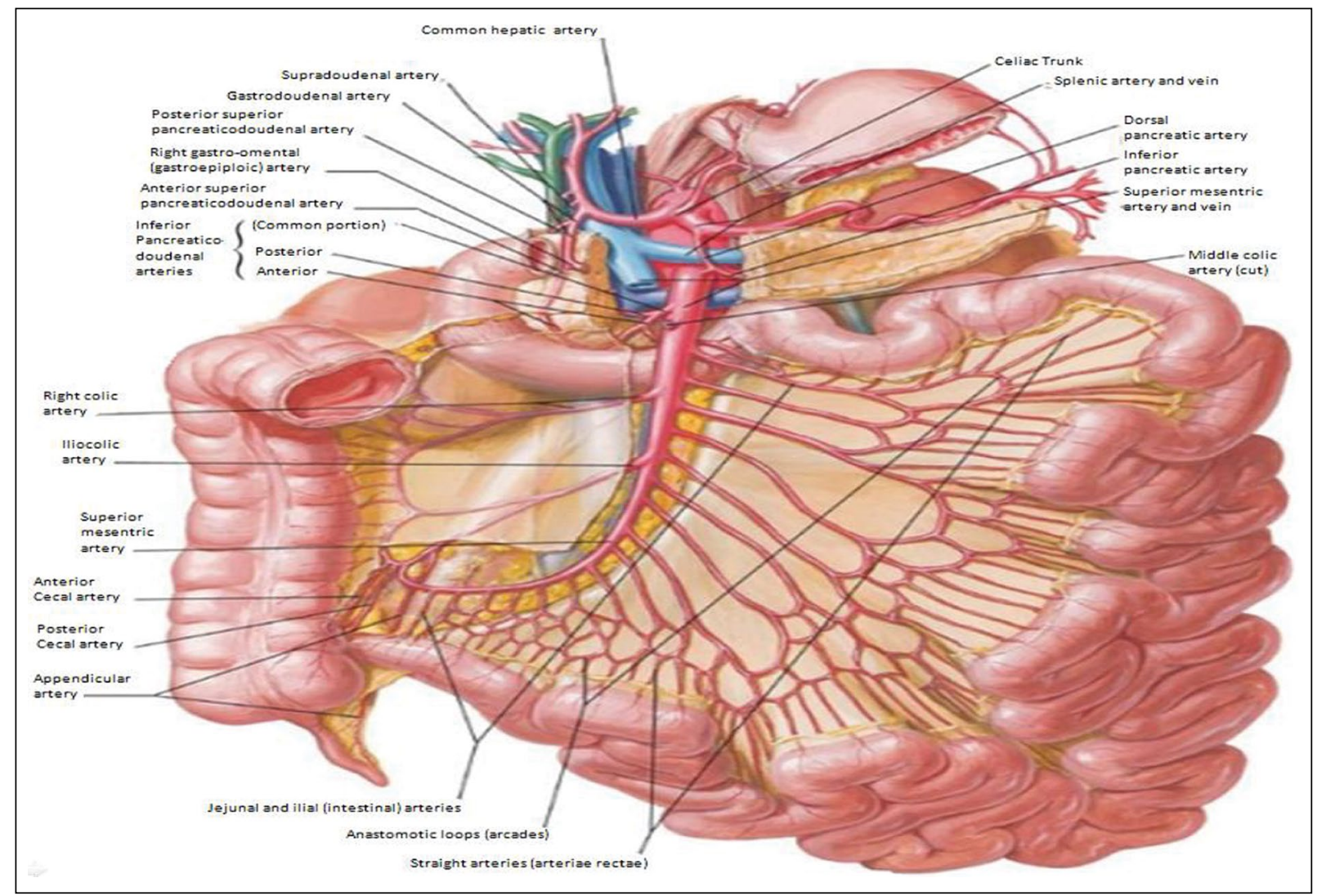

Figure 1. Normal anatomy of superior mesenteric artery and its branches [3].

artery, an odd right hepatic branch, or exceptionally the splenic artery or a cystic artery [14].

The aim of this work is to describe an unusual morphology or variation of superior mesenteric artery. The incidence and developmental significance of this variation are discussed, which will play an important role in conducting and planning of radiological and surgical procedures.

\section{CASE REPORT}

During our routine undergraduate gross dissection in abdominal region of a 38-year-old Sudanese male body cadaver ( $165 \mathrm{~cm}$ in length and $67 \mathrm{~kg}$ weight) at the Department of Anatomy, Collage of Medicine, University of Science and Technology in Sudan, it was noted that the superior mesenteric artery originated from the abdominal aorta in unusual manner $1 \mathrm{~cm}$ above the left renal vein, then made a unique unusual arch $2 \mathrm{~cm}$ over the confluence of inferior vena cava and left renal vein where descended down.

The superior mesenteric artery shared the same origin with the coeliac trunk as seen in Figure 2.
Variations were also noted in the origin of the right hepatic artery from the upper right part of the arch in that it ascended towards the hilum of the liver by $5 \mathrm{~cm}$ from the site of origin and it gave rise to right gastroomental artery branch where it gone to the back of the first part of the duodenum and then to the greater curvature of the stomach. It was also noticed that $3.75 \mathrm{~cm}$ from the origin of the gastro-omental artery, right hepatic artery gives rise to another unique gastroduodenal branch supplied just the posterior part of the first part of duodenum and gave no other branches.

\section{DISCUSSION}

Knowledge of visceral arteries variations is important to radiologist and surgeons. The superior mesenteric artery and its branches show a lot of variations and they had been reported in some literatures.

The usual pattern of classical anatomy of coeliac trunk, that it is divided into three main branches hepatic, splenic and left gastric arteries, can be found in $84-87 \%$ of humans [13], while incomplete bifurcation is seen in $13 \%$ of individuals. The coeliac trunk may 


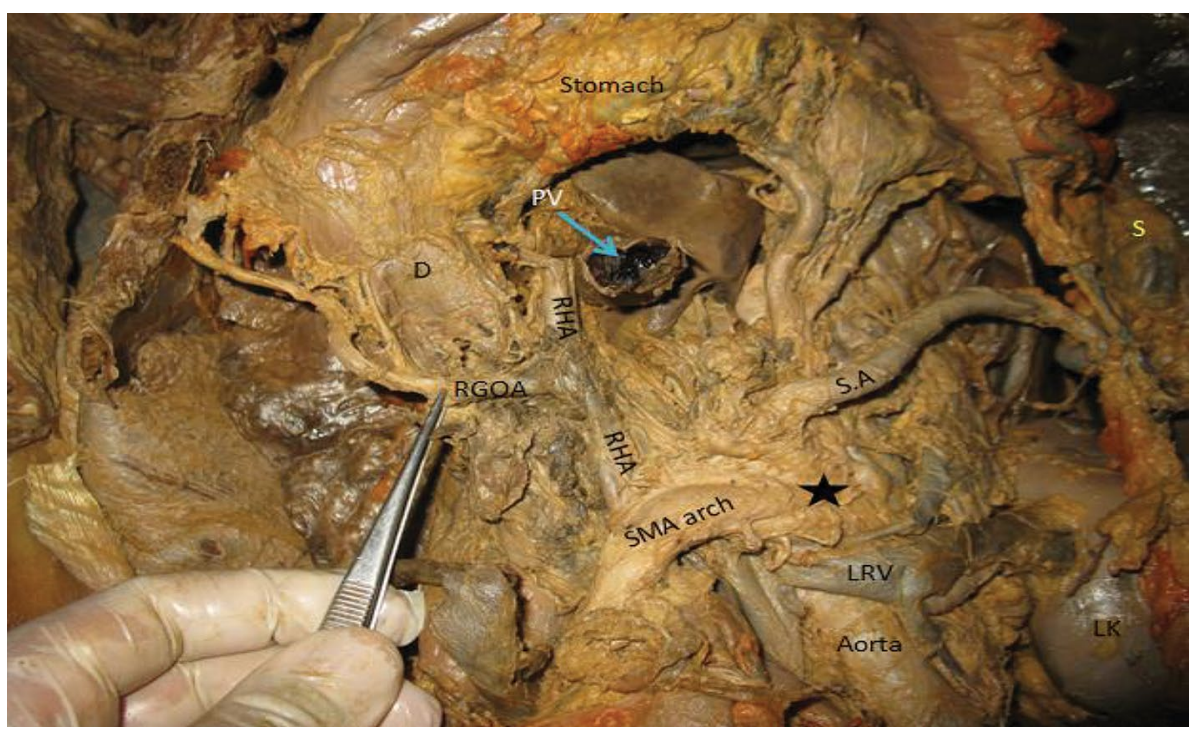

Figure 2. Right hepatic artery (RHA), superior mesenteric artery arch (SMA arch), left renal vein (LRV), splenic artery (S.A), right gastroomental artery (RGOA), gastro-duodenal artery (GDA), duodenum (D). Spleen (yellow S), left kidney (LK), portal vein (PV), common origin of superior mesenteric and coeliac artery (black star ${ }^{*}$ ).

be absent rarely, i.e. in $0.2 \%$ of reported cases [1]. Although the superior mesenteric artery arises $1 \mathrm{~cm}$ below the coeliac trunk, it supplies the midgut [15].

In this case we reported the coeliac trunk and the superior mesenteric artery arising from a common trunk. It was also noted that the right hepatic artery arise from the superior mesenteric artery which also gives rise to the right gastro-omental artery branch. The left hepatic artery arises from the coeliac trunk, so that the common hepatic is actually absent. This fact has a considerable importance in liver transplants.

Regarding the morphology of the superior mesenteric artery, it takes an unusual shape by forming an arch over the confluence of the inferior vena cava and left renal vein, where it descends down. In the normal condition it directs steeply downwards behind the splenic vein and the neck of the pancreas without forming arch.

The explanation of anatomical variation and pathological consequences of diseases which affect the mesenteric vasculature is that it may be due to changes occurring in the development of ventral splanchnic arteries which supply allantois, yolk sac and chorion. Initially the ventral splanchnic vessel develops as paired vessels and then unit in the median line to form four roots to supply the gut. The four roots then start to communicate by the ventral longitudinal anastomoses. In the normal condition the first three roots coalesce to form the coeliac trunk and the fourth root forms the superior mesenteric artery that migrates caudally to take its final classical position in the ventral surface of abdominal aorta below the coeliac trunk [8].

To highlight the importance of knowing visceral arteries variations and branching patterns in surgery we will address some of surgical aspects.

The pattern of extrahepatic arterial anatomy is not constant and can be highly variable. In approximately $25 \%$ to $75 \%$ of population the common hepatic artery arises from the coeliac trunk [7]. In the variant patterns, the hepatic lobes receive arterial flow through common hepatic artery or more than one branches that arise from the superior mesenteric artery, left gastric artery, or, rarely, from other arterial trunks [2].

Regarding the hepatic surgery, there are lots of variations in hepatic artery anatomy so that it is very important to keep it in mind and to detect it in performing hepatic surgery such as portal dissections, cholecystectomies and liver resections $[4,5]$.

On the other hand, it is very important to look for the variation of the hepatic artery to avoid its injury in performing surgical operations in the pancreas such as Whipple procedure (pancreaticoduodenectomy), which is performed to remove the tumours in the pancreas.

In our exceptional condition we think that the four roots coalesce to form a common origin for coeliac trunk and the superior mesenteric artery. Also, the separation takes place in higher level which leads to one of coeliac trunk branches originating from the superior mesenteric artery. 


\section{CONCLUSIONS}

Knowledge of visceral arteries variations and branching pattern is of immense significance during radiological investigations and surgical procedures for example liver transplants, in patients undergoing coeliacography for gastrointestinal tract bleeding, in case of aortic replacement with reimplantation of trunk and chemoembolisation of liver malignancies [12] and penetrating injuries to the abdomen which can potentially create morbidity and mortality. Finally we must keep in mind that vascular variations are usually asymptomatic.

\section{REFERENCES}

1. Adachi B. Anatomie der Japaner I. Das Arterien system der Japaner. Band II Kaiserlich-Japanischen Universitätzu Kyoto Kyoto, Maruzen. 1928: 20-71.

2. Braun MA, Collins MB, Wright P. An aberrant right hepatic artery from the right renal artery: anatomical vignette. Cardiovasc Intervent Radiol. 1991; 14(6): 349-351, indexed in Pubmed: 1756552.

3. Frank H. Netter MD. Atlas of Human Anatomy. 5th Ed. Saunders 2010: 205.

4. Gruttadauria S, Foglieni CS, Doria C, et al. The hepatic artery in liver transplantation and surgery: vascular anomalies in 701 cases. Clin Transplant. 2001; 15(5): 359-363, indexed in Pubmed: 11678964.

5. Jones RM, Hardy KJ. The hepatic artery: a reminder of surgical anatomy. J R Coll Surg Edinb. 2001; 46(3): 168-170, indexed in Pubmed: 11478014.
6. Moore KL, Persaud TVN, Torchia MG. The developing human clinically oriented embryology. 9th Ed. Saunders, Philadelphia 2011: 389-420.

7. Nelson $\mathrm{T}$, Pollak $\mathrm{R}$, Jonasson $\mathrm{O}$, et al. Anatomic variants of the celiac, superior mesenteric, and inferior mesenteric arteries and their clinical relevance. Clin Anat. 1988; 1(2): 75-91, doi: 10.1002/ca.980010202.

8. Oran I, Yesildag A, Memis A. Aortic origin of right hepatic artery and superior mesenteric origin of splenic artery: two rare variations demonstrated angiographically. Surg Radiol Anat. 2001; 23(5): 349-352, indexed in Pubmed: 11824137.

9. Sadler TW. Langman's medical embryology. 13th Ed. 2014: 225-249.

10. Sinnatamby CS. Last's Anatomy: Regional and Applied. 12th Ed. Elsevier/Churchill Livingstone Elsevier, Edinburgh 2011: 244-245.

11. Sinnatamby CS. Last's Anatomy: Regional and Applied. 9th Ed. Elsevier/Churchill Livingstone Elsevier, Edinburgh 1992: 326-327.

12. Sridhar Varma KS, Pamidi N, Vollala V. Common celiacomesenteric trunk: a rare anatomic variation. J Vasc Bras. 2009; 8(3): 271-273, doi: 10.1590/s167754492009000300015.

13. Van Damm JP, Bonte J. Vascular anatomy in abdominal surgery. Georg Thieme Verlag, Stuttgart 1990: 4-42.

14. Van Damme JP. Behavioral anatomy of the abdominal arteries. Surg Clin North Am. 1993; 73(4): 699-725, indexed in Pubmed: 8378817.

15. Williams PL, Bannister LH, Berry MM. Gray's anatomy. 38th ed. Churchill Livingstone, London: 1553-1554. 